\section{LA EXPEDICIÓN CIENTÍFICA AL RÍO HUALLAGA (PERÚ, 1948) Y LA BÚSQUEDA DE LA COHESIÓN SOCIAL}

THE SCIENTIFIC EXPEDITION TO THE HUALLAGA

RIVER (PERU, 1948) AND THE SEARCH

FOR SOCIAL COHESION

\author{
NÚRIA SALA · \\ Institut de Recerca Històrica - Universitat de Girona \\ (España). \\ E-mail: nuria.Sala@udg.edu
}

\section{Resumen}

Un estudio de caso, la expedición científica al Huallaga en 1948, sirve de hilo conductor a un análisis de la especificidad de las políticas de cohesión social en el Perú. A partir de fuentes institucionales, literatura profesional, obras e informes científicos se analiza el papel de la UNESCO y los saberes expertos en la definición de políticas científicas y de intervención social tendentes a lograr la cohesión social y el desarrollismo. Se muestra la importancia que tendrá el indigenismo en moldear tales presupuestos, en un periodo en el cual se fueron definiendo los saberes expertos competentes en la resolución del problema indio y la colonización amazónica, que convergería en la consolidación de la antropología aplicada a manera de instrumento clave de intervención social.

\section{Registro bibliográfico}

SALA, NÚRIA "La expedición científica al río Huallaga (Perú, 1948) y la búsqueda de la cohesión social», en: ESTUDIOS SOCIALES, revista universitaria semestral, año XXIX, $n^{\circ}$ 57, Santa Fe, Argentina, Universidad Nacional del Litoral, julio-diciembre, 2019, pp. 185-207.
Abstract

A case study, the scientific expedition to the Huallaga in 1948 , acts as a common theme to the analysis of the specificity of the social cohesion policies in Peru. Based on institutional sources, professional literature, scientific works and reports, the role of UNESCO is analysed along with expert knowledge in the definition of scientific and social intervention policies seeking to ensure social cohesion and developmentalism. The importance of indigenism in moulding these proposals will be shown, during a period in which the competent expert knowledge in solving the Indian problem and Amazonian colonisation, which was to concur in the consolidation of the anthropology applied as a key instrument of social intervention.

\section{Descriptores · Describers}

Perú / Amazonia - Cohesión social / Indigenismo / Saberes expertos

Peru / Amazon / Social cohesion / Indigenism / Expert knowledge

Recibido: 20 / 03 / 2019 Aprobado: 23 / 07 / 2019 


\section{INTRODUCCIÓN}

En 1948, el Instituto Internacional de la Hilea Amazónica (IIHA), creado en el seno de la unESCO, coordinó y financió una expedición científica al valle del río Huallaga, una zona estratégica para las conexiones viales y de navegación entre Lima y el Amazonas ${ }^{1}$. Se trató de un proyecto de investigación, que debía acompañarse de recomendaciones para resolver los problemas de colonización en la zona y estimar su potencial económico y de recepción de migrantes. Desde la perspectiva de un estudio de caso, buscamos ahondar en los debates y propuestas de políticas públicas para llevar a cabo la anhelada cohesión social en el Perú. Quisiéramos esbozar la influencia que en ello tuvo la cuestión étnica y ciertos saberes expertos, poniendo el foco en la Amazonia, una región que a menudo ha sido percibida en los márgenes del Estado y la sociedad nacional, al interiorizarse su débil integración territorial y de sus gentes, lo que en parte ha determinado en el Perú un sesgo historiográfico andinista.

Según Degregori, las obras de Cotler o de Fuenzalida, editadas en la década de 1960, pusieron el énfasis en «la educación, la migración y los procesos de organización y movilización campesina», en pos de finiquitar el aislamiento indígena y «encontrar vías alternativas de articular a la que entonces se denominaba «sociedad nacional, quebrando el viejo sistema de jerarquización étnica». Su visión contaba con un antecedente, José Uriel García, quien en 1929, y desde el indigenismo cuzqueño, había señalado en el cholo a ese «nuevo indio», un estereotipo humano que irrumpió, a partir de la década de 1950, "como grupo cojín entre mistis e indios o como clase emergente» (DEGREGORI, I995: 306-307)2. Modernización, desarrollo e integración nacional se entrelazaban con el indigenismo. La propuesta en ciertos círculos intelectuales era aplicar la observación participante e incidir en los profundos cambios que se producían en el Perú, cuando se resquebrajaba el sistema de dominación tradicional, que había marginado al indio. Tal y como ha expresado Osmar Gonzáles «el indigenismo es la expresión de un fracaso; la evidencia de una derrota, la no conformación de la nación peruana» (GONZÁLES, 2008). En consecuencia, el matiz introducido en el Perú, como también en otros

1] Este artículo y la colaboración en el dossier son resultado de la estancia de investigación en el CSIC en mayo-junio de 2018.

2] Un análisis de la obra de Cotler en el artículo de Martín-Sánchez de este dossier, para Fuenzalida ver DÍEZ (2011). 
países con una población indígena significativa, surgía de la necesidad de lograr la cohesión social y al mismo tiempo difuminar las identidades étnicas.

Giraudo y Martín-Sánchez han destacado la existencia de

un «campo profesional» del indigenismo, con sus instituciones, sus redes, sus actores, sus proyectos, sus luchas por dominar los capitales propios del campo y delimitarlo frente a otros sectores de las sociedades latinoamericana: partidos, burocracias estatales generalistas, organismos internacionales, etc. (MARTíN-SÁNCHEZ, 2OII: 15)

En la década de 1940, los especialistas en temáticas indígenas podían provenir de los más distintos campos, si bien se percibía cierta decantación hacia lo que décadas después sería el predominio de las ciencias sociales, sobre todo tras la institucionalización de la etnología. La antropología aplicada sería determinante en las políticas públicas desarrollistas en los años cruciales y transformadores de la realidad nacional del gobierno del general Juan Velasco Alvarado (1968-1975). Quisiera apuntar, que a la par se estaba definiendo lo que nos permitimos denominar un campo de saberes y profesional «tropical», que en parte analizaremos y contextualizaremos.

Este artículo se sustenta sobre una metodología diversa, deudora de la sugerida por R. González y J. Suriano en sus estudios sobre la cuestión/cohesión social en Argentina, que han abordado desde la perspectiva de los actores, redes de interacción y difusión, debates públicos y académicos, junto a su plasmación en políticas públicas (GONZÁLEZ Y SURIANO, 20I7). La investigación se sustentó en la revisión de literatura profesional — folletos, libros y revistas científicas, de instituciones académicas y profesionales-. La información concreta relativa a la expedición al Huallaga de 1948 — debates previos, informes de los científicos integrantes—, la hemos recabado en publicaciones oficiales - Organismo Coordinador de la Hilea Amazónica Peruana (осHAP)—, institucionales — Instituto Indigenista Americano y Peruano- o profesionales; y entre la documentación disponible generada desde la propia expedición y conservada, en versión inglesa y francesa, en el repertorio digital de unesco, junto a las notas de prensa insertas en el Correo de la Unesco. Las revistas, folletos y monografías se conservan dispersas en distintas instituciones peruanas - Museo de la Facultad de Medicina de la Universidad de San Marcos, Museo de la Cultura Peruana, Hemeroteca de la Biblioteca Nacional—.

El origen del estudio fue nuestro interés por comprender el papel de los saberes expertos en la colonización de la Amazonia peruana (SALA i viLA, 20I6). Inicialmen- 
te llamó nuestra atención el ejercicio profesional y los discursos de los ingenieros (SALA i vila, 2007) para, en una segunda etapa, orientarnos a los médicos, en especial aquellos cuya trayectoria se caracterizó por cierta especialización en medicina tropical y atención a las condiciones médico-sociales con tintes higienistas e indigenistas (CUETO, 1997 y 200I). El estudio de caso relativo a la Expedición al Huallaga fue escogido en un principio por haber participado en ella el patólogo Pedro Weiss, cuya obra ha llamado nuestra atención en años recientes.

\section{EL INSTITUTO INTERNACIONAL DE LA HILEA AMAZÓNICA}

La primera Asamblea General de Unesco convocada en París (1946) asumió la necesidad de promover el estudio de la Hilea Amazónica, en temas relacionados con las ciencias puras y aplicadas, —botánica, química, zoología, geología, meteorología, antropología, educación, nutrición y salud-, y definir modelos de intervención desarrollistas. La decisión surgió de una propuesta presentada por la legación de Brasil, a iniciativa de Paulo Estevão de Berredo Carneiro (I9OI-1982). Durante la Conferencia Internacional de UnEsCo, llevada a cabo en México DF entre el 3 de noviembre y el 6 de diciembre de I947, se creó el IIHA con el objetivo inicial de coordinar varios centros académicos regionales - Museo Amazonense, Museo Goeldi de Belén, Centro de Estudios Indigenistas de Colombia, Instituto Pasteur de Cayena-y de auspiciar proyectos científicos que implicaran a los países amazónicos y a los interesados en sus recursos y control geopolítico.

En la reunión de la Comisión Científica Internacional, celebrada en Belem do Pará, el I2 de agosto de 1947, se decidió convocar una reunión en Iquitos (Perú) para definir el programa y financiación. En el Perú, el gobierno de José Luis Bustamante (1945-1948) creó por Decreto de 20 de octubre de 1947 el organismo coordinador de la Hilea Amazónica (оснAP), adscrito al Ministerio de Relaciones Exteriores³.

3] Integrado por el asesor cultural del ministerio, los presidentes de: Sociedad Geográfica de Lima, Instituto Geológico del Perú, Sociedad de Protección de la Naturaleza; los directores de: Biblioteca Nacional, Archivo Nacional; seis miembros designados por el presidente de la República; representantes de los distintos ministerios y de los departamentos orientales. 
Se organizó en torno a un Comité administrativo bajo la presidencia del ingeniero Eduardo de Habich y una comisión dirigida por Luis Alayza y Paz Soldán ${ }^{4}$ Tras la decisión gubernamental cabe percibir una apuesta por validar en foros internacionales la política de colonización oriental basada en presupuestos de modernización técnica, como muestra que se propusiera una reunión preliminar en Tingo María (valle del Huallaga, departamento de Huánuco), que permitiría mostrar a los asistentes «los campos de experimentación, laboratorios y centros de estudio» 5 .

El proyecto del IIHA se basó en la posición de científicos e intelectuales como Julián Huxley ${ }^{6}$, primer director de UNESCO, o Joseph Needham, director de su división de Ciencias Exactas y Naturales, que defendían una agenda internacional científica, que coordinara las políticas nacionales desde instancias supranacionales. Needham, desde su experiencia en la China de la IIGM, defendía el «principio de periferia», que implicaba la irradiación desde un centro de los presupuestos modernizadores científicos — redes de cooperación, modernización de laboratorios, creación y actualización de bibliotecas especializadas, publicación, circulación y transferencia de los resultados de las investigaciones en revistas de referencia occidentales - Tal concepción se incardinaba con la agenda de desarrollo de Henri Laugier, secretario general adjunto de la onU, sintetizado en favorecer el saber científico,la exploración de recursos naturales, la resolución de los desequilibrios medioambientales, las desigualdades socioeconómicas y la resolución del problema de los refugiados pos IIGM (MAIO Y SÁ, 2000; MAIO, 2004 y 2005).

Solo contamos con estudios relativos al IIHA para el caso del Brasil. En conjunto demuestran su fracaso, en parte por las disensiones de los científicos locales respecto a las propuestas surgidas desde el «centro»-UNESCO. Triunfaron quienes defendían una ciencia nacional tutelada y financiada por el estado y que daría lugar a la creación del Instituto Nacional de Pesquisas da Amazônia (MagalHâes, silva Y MAIO, 2007; PETITJEAN Y DOMINGUES, 200I; MAIO Y SILVA, 2009; GIL-RIAÑO, 20I4). Veamos los avatares en el caso peruano.

4] Junto al contra almirante Federico Díaz Dulanto, Miguel Cavero Egúsquiza y los ingenieros Manuel Sánchez del Águila y Jorge de las Casas.

5] Organismo coordinador de la Hilea Amazónica Peruana (OCHAP), I, Hilea Amazónica, 1948.

6] «Sugestiones del Dr. Huxley. Para el progresso de la civilización universal», El Correo de la Unesco, I, 18/10/1948, pp. 1 y 6 . 


\section{LA CONFERENCIA INTERNACIONAL DE LA HILEA AMAZÓNICA EN IQUITOS (1948) ${ }^{7}$ Y LA EXPEDICIÓN CIENTÍFICA AL HUALLAGA}

Se desarrolló entre el 30 de abril y el ro de mayo de 1948 y participaron delegaciones de los países de la Hiela — Brasil, Bolivia, Colombia Ecuador, Venezuela y Perú ${ }^{8}$ pero también aquellos con intereses coloniales o académicos sobre la

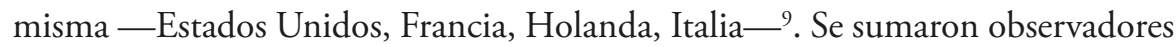
de Gran Bretaña, Suiza, Unión Panamericana, Consejo Internacional de Uniones Científicas, Conferencia Permanente de Altos Estudios Internacionales, Instituto Interamericano de Ciencias Agrícolas y la propia UNESCO $^{10}$.

El espíritu que inspiró la reunión fue el interés por convertir la selva en un lugar de promisión, para dar respuesta al desplazamiento de poblaciones pos IIGM. En la reunión de Belem do Pará, el peruano Luis Alayza y Paz-Soldán adjetivó la Amazonia cómo una «tierra de promisión», donde la labor de los científicos devendría en un «estímulo a las perspectivas de que llegue a construir para el hombre civilizado un verdadero Canaán». En el discurso inaugural de la Conferencia de Iquitos, Alayza subrayó que el interés científico «tiene por fin dar pan y patria a quienes lo necesitan» y en el contexto de la IIGM, el poder «ofrecer espacio y pan a los desventurados hijos del Viejo Mundo, que después de las últimas guerras languidecen hambrientos, perseguidos y sin patria», y cuya labor debía orientarse a los trópicos, puesto que

7] OCHAP, Hilea Amazónica, II, 1948. El Correo de la UNESCO, I, 05/06/1948.

8] Los delegados fueron: Brasil (Linneu Albuquerque de Mello, presidente, Heloísa Alberto Torres, Gastón César de Andrade); Bolivia (Martín Cárdenas, presidente, Luis Hertzog, Carlos Loayza Beltrán, Antonio Soruco), Colombia (Enrique Pérez Arbeláez), Ecuador (Rafael Alvarado, presidente, Robert Hoffstetter, Marco Bustamante), Venezuela (Tobías Lasser, presidente, William PhelpsJr, Nelson Himiob, J.T. Morillo Molina), Perú (Luis Alayza y Paz-Soldán, presidene, Federico Díaz Dulanto, Luis E. Valcárcel, Bolívar Ulloa, Gerano Dianderas, Jorge de las Casas, Pedro Weiss, Manuel Sánchez del Águila, Miguel Cavero Egúsquiza, monseñor José García Pulgar, Reynaldo Crespo y Jorge Atkins y Emilio Delboy).

9] Estados Unidos (Clarence Boonstra, presidente, Claud L. Horn, Allan R. Holmberg), Francia (Paul Rivet, Henri Mehu); Holanda (M. L.Savelberg); Italia (Mario Pavirani, Alessandro Volticelli).

10] Gran Bretaña (D.J. Parkinson), Suiza (J.A. Beger), Unión Panamericana (Ralph H. Allee), Consejo Internacional de Uniones Científicas y Conferencia Permanente de Altos Estudios Internacionales (Ángel Establer), Instituto Interamericano de Ciencias Agrícolas (Ralph H. Allee y Manuel Elgueta) y UNESCO (E.J.H. Corner, Emilio Arenales, Daniel Smith). 
«las selvas americanas duermen intactas, llenas de promesas, con miles de millones de metros cúbicos de madera, que solo reclaman la sierra y el tractor, lagos de petróleo, arenas de oro y hasta el tesoro, todavía insospechado del caudal humano el nativo de las tribus nómadas, que cuando se desarrolle la eugenesia, permitirá modelar al hombre nuevo, con las aptitudes que le faltan $»^{11}$.

Tierras de promisión para los desplazados, recursos naturales por explotar, eugenesia sobre los grupos étnicos, que las poblaban y a la vez las abstraían del imaginario de progreso he ahí varias de las ideas fuerza que se planteaban. La llegada de nuevos migrantes y el extractivismo económico debían ir de la mano de revertir la renuencia de los aborígenes a integrarse en la economía productiva y la nación.

En la reunión de Iquitos se organizaron las propuestas y debates en torno a dos comités, el científico y el económico. Por su interés y relevancia para nuestros intereses cabe destacar las intervenciones de Paul Rivet y de Allan R. Hombert, representantes en cierta forma de los intereses académicos (y políticos) franceses y norteamericanos sobre la región. Holmberg de la Universidad de Cornell tendría una influencia significativa en el devenir científico peruano desde la dirección del Proyecto Vicos, que introdujo la antropología aplicada en el país; Rivet, fundador del Instituto de Etnología (1926) y del Museo del Hombre (1937) de París, mantenía excelentes relaciones con la etnología americana — estuvo exiliado durante el gobierno de Vichy en Colombia, donde fundó el Instituto y Museo de Antropología, y en México-, estudioso de los jíbaros, era partidario de la misión social y cultural edificante de la antropología, orientada a educar al pueblo y a reformar las mentalidades (LAURIÈRE, 2008). En Iquitos, Rivet defendió que «era indispensable el mejoramiento de las condiciones de vida de la gente que había en la región; tanto aborígenes como inmigrantes» y, sobre la base de su experiencia en la Misión Geofísica Francesa al Ecuador (I90I-1906), defendió un modelo de intervención científica ${ }^{12}$. A su vez Holmberg destacó el papel asumido por Estados Unidos en analizar científicamente «los problemas amazónicos» y puso en valor

11] «Acta de la sesión inaugural de la Segunda Conferencia Internacional de la Hilea Amazónica, en Iquitos 30/04/1948», OCHAP, II, 1948.

12] Rivet destacó la proyección científica francesa y destacó una misión en el Alto Amazonas (Chinchipe), en colaboración con el Perú, o la prevista fundación de un instituto de investigaciones en la Guayana francesa. 
las llevadas a cabo por norteamericanos en Bolivia, Brasil, Colombia, Ecuador, Perú y Venezuela entre 1946-1947. ${ }^{13}$ Una revisión de la bibliografía citada en los informes finales, permite constatar que en la elección del Huallaga pudo influir estudios previos en el marco de la cooperación político científica Estados Unidos-Perú llevada a cabo durante la IIGM y durante el gobierno de Manuel Prado (1939-1945), entre los que destacaremos por su proyección posterior los efectuados desde la Universidad de Cornell, sin que se pueda obviar las llevadas a cabo por técnicos del ministerio de Agricultura peruano.En ambos casos se percibe el papel central otorgado a la ciencia para moldear los planes de integración territorial e indígena, junto a la modernización y desarrollo productivo de la Amazonía; unidos a intereses geopolíticos, en el contexto de la IIGM, por asegurarse materias primas esenciales — caucho, farmacopea, pesticidas- (CUVI, 2OII), seriamente amenazados tras la ocupación japonesa de zonas clave del Pacífico.

Se tomaron diversos acuerdos: la sede del IIHA se situaría en Manaos, coordinándose con centros amazónicos sitos en Archidona, Iquitos, Riveralta, Atabo, Simudo y otros; recopilar información bibliográfica amazónica y promover la edición de fuentes; promover, coordinar y divulgar estudios específicos sobre aspectos hidrobiológicos, geofísicos, biogeográficos, meteorológicos y problemas agrícolas; solicitar ayuda técnica a los estados miembros; dar importancia capital al estudio humano — adaptación medioambiental, nutrición, prevención sanitaria, saneamiento-, porque en palabras del asesor peruano Jorge Atkins «del estudio de las poblaciones actuales de la selva se pueden sacar las más útiles consecuencias para las migraciones posteriores»; elaborar una Carta Geográfica de la Hilea Amazónica; y actuar específicamente en áreas geográficas limitadas, optándose por organizar una primera expedición científica en el valle del río Huallaga, en el Perú ${ }^{14}$.

13] En concreto, se refirió a experiencia de colaboración entre: el Office of Foreing Agricultural Relations con el Ministerio de Agricultura del Perú en la Estación Experimental de Tingo María; junto a varias campañas de investigación auspiciadas por: Instituto of Social Anthropology de la Smithsoniana, Museo de Historia Natural de Chicago, Jardín Botánico de Nueva York y las Universidades de Stanford, San Luis, Pennsylvania y Minnesota.

14] OCHAP, II, Hilea Amazónica, 1948. El Correo de la UNESCO, I, 06/07/1948. 
En el prólogo de la edición del Informe sobre el Huallaga (1950), Emilio Delboy sintetizó el interés peruano en el proyecto científico que comprendía la región del río Huallaga, una zona que «carece de esos deslumbramientos en que suele ser tan pródiga la Amazonía salvaje. Nunca fue el Dorado del caucho y la siringa, y no ofrece como ocurre más al norte y al Oriente, el señuelo de tierras interiores desconocidas, verdaderas provincias por conquistar». Y, sin embargo, era una «arteria estratégica» en las comunicaciones entre Lima y la costa-sierra y el Ucayali y Amazonas. Se trataba de una unidad hidrográfica aparte: comercial, social, agrícola y geomorfológica», que podía devenir en "una colonización de raigambre seguro porvenir», siempre que se articulara a través de redes viales — carretera y ferrocarril— con el deseable eje de comunicaciones terrestres entre Lima e Iquitos. En consecuencia, los resultados científicos obtenidos debían orientarse hacia: a) la convocatoria de un Primer Congreso Amazónico Nacional; b) promover el estudio y humanización de la Amazonía; c) tomar medidas proteccionistas respecto los bosques tropicales; y d) crear un ministerio de Oriente y Colonización (ISH, I950: 6-9).

La dirección de la expedición recayó en Cándido Bolívar (Madrid I897-México 1976) ${ }^{15}$, entomólogo, y estuvo integrada por Ramón Ferreyra (Callao I9IO-2005), ${ }^{16}$ botánico, Gerardo Dianderas (I888-I952) y Edwin B. Dorán Jr. (I918-1993) ${ }^{17}$, geógrafos, Aníbal Buitrón, antropólogo, y Pedro Weiss, patólogo ${ }^{18}$. Se orientaba hacia un modelo multidisciplinar que incluía las ciencias naturales y humanas, si bien prestaremos atención a sus conclusiones y propuestas sobre las características y condiciones de vida de sus habitantes y el estudio de las enfermedades predominantes. ${ }^{19}$

15] Entomólogo, zoólogo, y espeleólogo. Fue profesor de zoología en la Facultad de Ciencias de la Universidad Central de Madrid y secretario de Manuel Azaña en 1939. Exiliado en México estuvo vinculado al Colegio de México, a la Escuela Politécnica y el Instituto de Salubridad y Enfermedades Tropicales y fundó la revista Ciencia.

16] Estudió en la Universidad Mayor de San Marcos, doctor en taxonomía vegetal por en la Universidad de Harvard (1942-1945). Profesor de la UNMSM, director del Museo de Historia Natural (1948-1981), donde formó el herbario San Marcos (USM), a partir del material recolectado en el Huallaga.

17] Dianderas era director del Instituto de Geografía de la Facultad de Letras de la Universidad de San Marcos y Doran era profesor de la Universidad de Cornell.

18] Según E. Delboy, fue incorporado a ella por su experiencia profesional, como reconocido patólogo y especialista en enfermedades tropicales (ISH, 1950: 5).

19] «Rapport sur les mesures prises par l'UNESCO en 1948 en vue de la creation de l'IIHA», UNESCO/ HS/IIHA/12, Paris, 10/09/1948. 


\section{LOS INDIOS EVANESCENTES Y EL «NUEVO INDIO» DEL HUALLAGA}

Los proyectos de cohesión social que subyacían en el proyecto fueron palpables en las observaciones y reflexiones sobre la identidad étnica o política de varios de los miembros de la expedición. Si bien varios de los informes prestaron atención a la realidad humana regional o las expectativas migratorias, los informes más significativos salieron de la pluma del antropólogo ecuatoriano Aníbal Buitrón, de su asistente y estudiante de etnología Mario Vázquez y del patólogo Pedro Weiss. En el primer supuesto cabe citar que tanto el geógrafo Edwin B. Doran cómo Cándido Bolívar señalaron el potencial migratorio de las riberas del Huallaga para devenir un centro de colonización; si bien el primero puso el énfasis en el reto que suponían sus deficientes comunicaciones terrestres ${ }^{20}$ y el segundo, tras anotar de forma optimista que podría atraer en torno a un millón y medio de habitantes y convertirse en una "positiva reserva para la especie humana», defendía la necesidad virar hacia políticas de protección de la naturaleza, con la creación de un Parque Nacional o de una Reserva Biológica (ISH, I950: 3 ).

El estudio de la población indígena del Huallaga se encargó inicialmente a Alfred Metraux (MÉTRAUX, I949: I74) ${ }^{21}$, quien acababa de editar, junto a Julián H. Steward, una obra de referencia sobre los indios de la Amazonía peruana y ecuatoriana (STEWARD y MÉTRAUX, 1948). Según el propio Metraux, prefirió delegarla tarea en A. Buitrón al considerarle un especialista en poblaciones indias y mestizas, asimiladas a la cultura hispano-americana (MÉTRAUX, I949: 177)22. Este se había doctorado en la Universidad de Chicago (1945), orientándose al estudio de caso de comunidades indígenas exitosas (BUITRón, I942 y 1947) ${ }^{23}$ y a la docencia en la Universidad de Quito ${ }^{24}$. Antes de ir al Huallaga,había situado las raíces del

20] UNESCO/HS/IIHA/12, Paris, 10/09/1948: 18.

21] Para un análisis de la relación de Metraux y los Andes ver Auroi (2004).

22] La elección inicial de A. Metraux pudo obedecer al hecho que en 1948 se hubiera editado su trabajo sobre los indios de la Amazonía peruana y ecuatoriana (STEWARD Y MÉTRAUX, 1948).

23] Obras financiadas por la Universidad de Chicago, el Viking Fund de Nueva York y el Instituto Nacional de Previsión del Ecuador.

24] Posteriormente, junto a John Collier Jr. (1949), fue uno de los iniciadores de la antropología visual y colaboró: en planes de antropología cultural aplicada entre indígenas del Altiplano ecuatoriano bajo el auspicio del Instituto de Previsión Social y del Instituto de Antropología de Quito; con el Instituto Indigenista Ecuatoriano (1943-1974); y fue consultor internacional de Naciones Unidas. No nos consta que volviera a incursionar en estudios de antropología amazónica ni relacionados con el Perú. 
problema del indio en la carencia o mala calidad de las tierras étnicas disponibles, su ignorancia, el alcoholismo, los dispendios en fiestas religiosas, junto a la opresión y malas artes que soportaban de las autoridades civiles y de abogados y tinterillos en sus litigios.Para revertir la situación, en su opinión, se requerían políticas de reparcelación de la tierra, auspiciadas por el Seguro Social ecuatoriano, vía la adquisición de haciendas para su posterior asignación a campesinos-indios; misiones sociales y culturales para introducir principios higiénicos, prevención y tratamiento de enfermedades, eficiencia en la agricultura y ganadería, pequeña industria, creación de escuelas y centros de alfabetización y organización de centros de lectura y actos sociales. Un vasto plan, que requería de un efecto propagandístico que se lograría con una experiencia piloto (BUitrón, 1948).

Buitrón reunió en su «informe sobre el reconocimiento etnológico del valle del Huallaga» una serie de consideraciones sobre demografía, hábitat, vestido, alimentación y economía además de varias consideraciones sobre grupos sociales o étnicos, sus formas culturales y prácticas sociales, religiosas y políticas (ISH, I95O: I25-I75). Clasificó sus habitantes étnicamente y en función de su posición social, económica y grado de cultura. En la cúspide social situó a una minoría de comerciantes, que, junto a los funcionarios, compartían determinadas formas culturales, matizando que el registro civil solo inscribía en la categoría de blancos a los hijos de italianos, españoles o ingleses, para concluir que gran parte de la población era mestiza. A su entender solo se podían considerar indios a los lamas radicados en el pueblo homónimo, donde se les segregaba a determinados barrios. Mantenían prácticas sociales, religiosas y culturales propias y privativas, entre tanto, ciertos mestizos actuaban de intermediadores económicos. Los barrios indios carecían de colegios y en la zona no existían escuelas especiales para indígenas, por lo que la mayoría de los lamas eran analfabetos (BUITRón, I948: I48-52).

Según Buitrón, pocos habitantes mostraban interés por la política, aunque ello no obviaba cierta división entre civilistas o reaccionarios (sic) y apristas. Los primeros eran comerciantes, propietarios o cargos gubernativos locales, defensores de sus intereses particulares. El APRA había calado en la mayoría de la población, su sede partidaria estaba en Uchiza y difundía su ideario a través de dos revistas de ámbito regional, Renovación, editada desde 1945 en Uchiza, y la Voz de Tocache. El ambiente político variaba según las poblaciones, así en Lamas las autoridades se aseguraban antes de dar respuesta a cualquier reclamación cuál era el sentido del voto de los demandantes, en otros pueblos se detectaba cierta fiebre electoral en las 
campañas por el voto y excepcionalmente, en el caso de Saposoa, ambas facciones habían afrontado unidas varias obras públicas, en especial una pista de aterrizaje ${ }^{25}$.

Lo descrito apunta a la existencia de un sentir difuso de deseos de cambio político, que condujera, a través de políticas populistas, a una mayor y mejor redistribución de los recursos y a ampliar la política social estatal. Una realidad, que en cierta forma se complementaba con la orientación científica de Buitrón cuando se posicionó en favor de la adopción de políticas desarrollistas y de inclusión social basadas en promover la educación y la salud, lo que le llevó, a su vez, a destacar el papel de los misioneros evangélicos en Bellavista, Yurimaguas y Lamas donde «su preocupación inmediata ha sido la organización de escuelas y hospitales», una estrategia que había sido asumida por los pasionistas y obviada por los adventistas ${ }^{26}$.

En sus conclusiones finales Buitrón afirmó que el valle del Huallaga no debía ser considerado un espacio característico de la Amazonía ya que la mayoría de sus habitantes eran «mestizos cultural y, en gran parte, también racialmente» y no era una región aislada, como evidenciaba la existencia en la mayoría de pueblos de pistas de aterrizaje y un servicio regular aéreo. El único grupo indígena existente era el de los lamas, cuyo conocimiento y futuras investigaciones, en especial sobre su cultura y adaptación al medio geográfico, permitirían «resolver muchos problemas acerca del origen, contacto, migraciones, mestizaje, etc. de muchas tribus de la Cuenca Amazónica». En consecuencia, creía que el proyecto debía proseguir en una región diametralmente opuesta al Huallaga y que estuviera caracterizada por ser «una zona aislada y de difícil comunicación con el mundo exterior, donde la población es indígena, nativa de la selva», recomendando el valle del río Pastaza en los límites entre Perú y Ecuador ${ }^{27}$.

Pedro Weiss llegó al Huallaga tras una larga trayectoria de estudios sanitarios sobre la selva en el Madre de Dios (I924) (WEISs, I924); La Convención y valles de Paucartamboen Cusco (1934) (Bustíos, 20I4: 5I) y Yurimaguas (I942) (weiss, URTEAGA Y GONZÁLEZ, I942), regiones asoladas por sucesivas epidemias que habían

25] UNESCO, NS/IIHA/18A, 17/12/1948, pp. 28-29. En la edición publicada en el Perú del Informe del Huallaga se eliminó el apartado dedicado a la política, quizás por las referencias al APRA, en una coyuntura de represión tras el intento insurreccional aprista de 1948.

26] UNESCO, NS/IIHA/18A, 17/12/1948, p. 153. Las referencias señalan las distintas misiones católicas y evangélicas activas en la zona.

27] UNESCO, NS/IIHA/18A, 17/12/1948, p. 175. 
frenado el proceso de colonización. Sus informes previos y sobre el Huallaga evidencian una metodología multidisciplinaria: recopilación de información en pos de la historicidad de las enfermedades endémicas y epidémicas — crónicas coloniales o de exploradores y viajeros, misioneros- o de datos médicos fehacientes, que, para el caso de Tingo María, Saposa y Lamas en el Huallaga, provenían de la labor llevada a cabo en la región por el Servicio Inter-Americano de Salud-Pública; junto a la evaluación sanitaria a partir de entrevistas a los pacientes, análisis de laboratorio y elaboración de historias clínicas para el mayor número de habitantes posible. Además, y según sus propias palabras, recurrió a «investigaciones médico-sociales, condiciones de vida y de trabajo» y combinó «el análisis clásico con la valoración social». Investigador multifacético, en palabras de su alumno Uriel García, fue un «biólogo humanista» y «fundamentalmente un médico y como tal fue un patólogo; es decir un biólogo que estudió la amplia gama de factores que influyen sobre la vida» y que se movería en el "campo de nadie», que le abriría a múltiples campos (GARCÍA, 2009: 400-404). El campo de nadie deviene en metáfora para enfatizar su voluntad multifacética e ilustra sobre un tiempo de fronteras difusas en la especialización científica.

Weiss concluiría que los males del Huallaga se debían a la mala organización familiar, déficit nutricional, parasitismo intestinal, alcoholismo y falta de asistencia, junto al «bajo nivel económico y social, a la falta de cultura sanitaria y técnica» (ISH, I950: II6). Sus recomendaciones fueron más allá de una propuesta meramente médica o farmacológica al señalar que progreso regional solo sería posible con la «acción directriz inteligente y pequeña ayuda económica del Gobierno» y con un plan que tuvieran en cuenta los siguientes objetivos: a) diversificación agrícola y manufacturas; creación de plantas piloto para el beneficio de productos locales destinados a la exportación y al consumo local —aceite y mantequilla de maní, aceite de ricino y productos del coco para la exportación, industria de yute y oleaginosas-; b) mejora de los métodos de trabajo; c) educación en medicina preventiva, fomento de la moral biológica; d) reforma integral de la educación, relegando la formación humanista en aras de una formación basada en los conocimientos técnicos, que incidiera en los principios de la medicina preventiva, agricultura, nutrición y aprovechamiento de los recursos naturales, que frenara la migración constante de los mejor formados (ISH, I95O: II6). Prestó atención especial al caso de los indios lamas, quienes con un «cuadro serológico común del indio americano puro» del 92,50, eran valedores de una unidad étnica y cultural desde 
tiempos incaicos, acentuada por el secular rechazo social que padecían. Valoró positivamente su modus vivendi y afirmó que «constituyen el elemento humano mejor dotado para la vida en la selva», con una «organización social superior» a la de cualquier otro grupo étnico:

«El encaje ecológico de los lamistas al medio de la selva, aprovechando elementos culturales andinos, selváticos y occidentales en forma conveniente, superior, biológicamente hablando, al logrado por la cultura mestiza criolla, es uno de los aspectos sociológicos interesantes del Perú» (ISH, I950: 84).

Concluía que "por una estrechez de miras» la única acción del estado iba encaminada a «asimilarles a la cultura mestiza, destruyendo su estructura social y manera de ser, sin reparar en sus cualidades», una realidad que, a su entender, «ha perturbado el problema indígena en todos los tiempos» (ISH, I95O: 89).

Una década después de su estadía en el Huallaga, Weiss publicó un artículo dedicado a los lamas "pueblo misterioso y legendario», en que reconocía que los datos médicos en que se basaba procedían de 1948 y los de índole social habían sido recopilados entonces por su esposa, que le acompañó en el viaje. Insistía en que los lamas estaban mejor dotados para la vida en la selva y para colonizar terrenos vírgenes, que cualquier otro habitante de la región, con mayores niveles de nutrición y robustez que los mestizos del valle (weIss, I959).

Según testimonio personal de uno de sus ayudantes, Javier Arias Stella, vivieron una paradoja al llegar al Huallaga, al constatar contra todo pronóstico, que los lugareños transportaban sus productos en balsas hasta Yurimaguas, primer puerto navegable e inicio de la travesía a Iquitos, capital del departamento de Loreto en el río Amazonas; para sortear el regreso a contracorriente, con avionetas de la IIGM que hacían el servicio entre los distintos pueblos del valle. El dato fue incorporado por Buitrón en su informe, no así la conclusión analítica de Arias Stella, quien los identificó con «nuevos indios»" ${ }^{28}$; un concepto desarrollado como apuntamos anteriormente por el indigenista cusqueño José Uriel García. Sobre tal análisis, cabe apuntar que el otro ayudante de Weiss fue Uriel García, hijo del indigenista. Cabe entonces presuponer, que en la percepción de la realidad indígena del Huallaga

28] Entrevistas personales a los patólogos Javier Arias Stella y Uriel García. 
entre Weiss y sus colaboradores tuvo cierta influencia el indigenismo cusqueño de las primeras décadas del siglo $\mathrm{Xx}^{29}$.

Las relaciones entre Buitrón y Weiss no siempre fueron fluidas, al mismo tiempo que divergían en su interpretación de la realidad social. Si para Buitrón había que ir a los confines de la selva para encontrar al indio, sujeto de estudio por excelencia, para Weiss y su entorno, los lamas emergían como modelo de grupo étnico cuyo estudio podía dar las pautas de adaptación al ecosistema tropical y convertir en exitosa la colonización de la región. Adaptación al medio y emergencia del «nuevo indio», capaz de asumir los retos de la modernidad y adecuarse a las nuevas condiciones de transporte y mercado, devenían en las divisas de la mirada científica de raíz nacional peruana.

Mario C. Vázquez actuó de asistente de Buitrón. Era alumno de etnología en la Universidad de San Marcos y con anterioridad había sido asistente en una investigación etnográfica sobre las condiciones y costumbres sociales de los indígenas del valle de Satipo y del lago Titicaca, auspiciada por el Instituto de Etnología de la Universidad de San Marcos y el Museo de Historia Natural de Lima. De su experiencia en el Huallaga surgió su tesis de grado sobre sus primitivos pobladores y las causas de su desaparición con la que se graduó de bachiller en Humanidades con mención en Etnología en 1949 (VÁzQUEZ, 1949). En ella analizaba los antecedentes históricos de los grupos étnicos del Huallaga - muyupampinos, carasblancas, caparusos, lamistas o motilones - y las causas de su desaparición —invasión portuguesa, sublevaciones, epidemias, conquista con fines o no religiosos, emigración, latifundismo-. Aunó la antropología histórica basada en los testimonios históricos regionales, con especial énfasis en la crítica de fuentes misionales por hallarse sujetos «a los prejuicios religiosos» (vázQuEz, I949: I-III), el estudio de caso fruto de la observación participante y la inmersión en una realidad ajena. Reconocía la influencia que ejerció sobre su investigación la obra de Gunter Tessmann Die Indianer Nordost Perus editado en 1930, y el «t. III del Instituto Smithsoniano, donde se dedica un capítulo a las tribus del Huallaga», con referencia a Steward y Métraux (1948).

29] Pedro Weiss era amigo personal de J.C. Tello, arqueólogo y médico de formación, con el que colaboró al menos desde 1919 en temas de paleo-patología. 
Según Vázquez, la desaparición de los distintos grupos aborígenes se produjo a raíz de la expansión del ingenio azucarero, que les subordinó como peones. Mal pagados, peor tratados y alcoholizados, unos migraron, siguiendo el curso de los ríos, soportando cambios de hábitat y tensiones con otros grupos, cuya consecuencia fue el aumento de las tasas de mortalidad y la quiebra de su identidad, llegando a afirmar que «el selvícola del Huallaga ha sufrido una verdadera desintegración cultural» (vÁzQUEZ, 1949: 98-99). La incorporación de la selva a la civilización había comportado dos realidades opuestas: aprovechar sus riquezas naturales y «la extinción del elemento nativo del Huallaga» (vázQUEZ, I949: IOo). Y, sin embargo, los lamas o lamistas, eran «el único grupo indígena que conservaba gran parte de sus primitivos rasgos culturales» (VÁzQUEZ, 1949: 99). Les consideró descendientes de las chancas y siguiendo la tradición oral, situó su hábitat original en el río Mayo, de donde se dispersaron hacia el Alto y Bajo Huallaga, en las cuencas de los ríos Cainarachi y Sisa, a raíz de una sublevación en las primeras décadas del siglo xx, descontentos por el control comercial de los mestizos y la construcción del aeropuerto. Su hábitat disperso, se complementaba con su residencia estable o estacional en el pueblo de Lamas, donde el barrio de Nalca era su residencia temporal en las festividades, ocasionales gestiones o para asegurar la escolarización de sus hijos.

Vázquez describió en su tesis a los lamas atendiendo a sus actividades económicas, división sexual del trabajo — hombres agricultores y cargadores, mujeres cocineras, artesanas textiles y ceramistas — relaciones familiares, festividades, religión y magia, relaciones con los mestizos y lengua (vázQuez, 1949: 45-56). Quizás porque era consciente de basar su tesis en datos etnológicos insuficientes, sugería la pertinencia de profundizar en el conocimiento de las prácticas sociales de los lamas, porque sería un «estudio útil para preparar la incorporación de aquellos, con un criterio científico a la civilización, iniciando con ello el primer paso hacia la Antropología Social Aplicada, en el Perú» (vázQuez, 1949: 57). Como constatamos en la cita textual que hemos entresacado de su texto, elaboraba el germen de la antropología social aplicada en el Perú, un tema que desarrollaremos en el siguiente apartado. 


\section{DE LA INSTITUCIONALIZACIÓN DE LA ETNOLOGÍA A LA ANTROPOLOGÍA APLICADA}

El Primer Congreso Indigenista Interamericano -Pátzcuaro, $1940-{ }^{30}$ y el Instituto Indigenista Interamericano devendrían en las plataformas e instituciones que marcaron las políticas indigenistas estatales en diversos países americanos (GIRAUDO, 2006: 6-7). En el Perú, la institucionalización de la antropología académica y del indigenismo tuvieron lugar durante la presidencia del arequipeño José Luis Bustamante y Rivero (1945-1948), con un papel destacado de cusqueño Luis E. Valcárcel en su etapa de ministro de Educación (1945-1946).

Valcárcel llegó al cargo avalado por su trayectoria intelectual e indigenista, cuando era director del Museo de Nacional (I93I-1945) y editor de la prestigiosa Revista del Museo Nacional desde su creación en 1932. Promovió la reforma universitaria con el objetivo de orientarla a «estudiar, investigar y propagar todo lo relativo al conocimiento humano en provecho de la colectividad», para lo cual debía potenciarse la formación técnica y profesional, si bien como el mismo escribió «me interesaba sobremanera: los avances que la investigación etnológica experimentaba en el país, a la luz de los cuales el Perú aparecía como un país inexplorado, como una tierra ignota que los nuevos hombres aún no habían llegado a dominar», para lo cual se crearon en la facultad de Letras de la Universidad de San Marcos, las especialidades de etnología, arqueología y geografía. Según el propio Valcárcel, la edición en 1945 de los primeros estudios de «Mishikin, Fejos, Gillin y Tschopik terminaron por convencernos del positivo aporte que la etnología significaba para el conocimiento del país, pero no podíamos seguir dependiendo de que llegaran investigadores de fuera». En el diseño del plan de estudios se tuvieron en cuenta las recomendaciones de Julián H. Steward, vinculado a la Smithsonian Institution e inspirador del Handbook of South American Indians (VALCÁrCEL, 198I: 354-5).

En 1946 se creó el Instituto de Etnología de la Universidad de San Marcos, cuya dirección asumió el propio Valcárcel, que compatibilizó con la dirección del Museo de la Cultura Peruana (1946-1966) que se preveía incluyera asimismo un Instituto de Etnología. El primero priorizaría la docencia y el segundo la investigación, si bien su ímpetu inicial se diluyó ante la escasa financiación estatal,

30] La delegación peruana estuvo compuesta por José Ángel Escalante, José Uriel García y Genaro Bedoya Sáez y, en calidad de invitados por el gobierno mexicano, por Hildebrando Castro Pozo, José Antonio Encinas y José María Arguedas, todos ellos significados indigenistas, aunque con diversidad de tendencias y proyección intelectual (GONSALES, 2011: 137-138). 
orientándose a elaborar "pequeñas monografías de pueblos costeños y serranos... dejando para más adelante los trabajos en la selva y estudios de mayor envergadura» (VALCÁRCEL, I98I: 364).

El Instituto Indigenista peruano se creó en 1946, supeditado al Ministerio de Justicia y Trabajo, bajo la dirección omnipresente de Luis E. Valcárcel. Dos años después, en 1948, se iniciaba la edición de su órgano de difusión, Perú Indígena. Su objetivo era sentar las bases de la intervención del Estado para resolver el problema del indio, ofrecer garantías a las propiedades de las comunidades, orientarles económica y culturalmente, mejorar sus condiciones higiénicas y sanitarias, proteger su producción artesanal e industrial, organizar cooperativas de producción y consumo e introducir el crédito rural para lograr la modernización del agro (GONSALES, 20II: I45). Tras un inicio vacilante, sería reorganizado en 1948 bajo la dirección de José Antonio Encinas, en parte para garantizar el II Congreso Indigenista Interamericano (Cusco, 1949), en cuyas conclusiones se acordó elaborar «una Geografía Médica de las principales zonas en que habitan las poblaciones indígenas de América, fomentando especialmente los estudios climatológicos», lo que muestra la influencia que ejercía la medicina social en el indigenismo peruano. En tal sentido, O. González señala el papel destacado que le cupo al médico Carlos Monge, quien sería director del Instituto Indigenista, y al Instituto de Biología Andina, aunque el precedente, a nuestro entender estuvo en Pedro Weiss, nombrado primer presidente de la Comisión de Antropología del Instituto Indigenista peruano en junio de $1949^{31}$. Un dato que debemos contextualizar dentro de la incipiente profesionalización de los saberes expertos indigenistas y fruto de un tiempo en el cual las fronteras científicas eran difusas, pero que a la vez nos ayuda a valorar la trascendencia de la obra de Weiss y de sus análisis médico-sociales.

El proyecto Vicos (1952-1962), dirigido por Allan R. Holmberg, fue uno de los programas emblemáticos de la antropología aplicada en el Perú, que aunó el estudio de caso y la intervención desarrollista y modernizadora (MITCHel, 20Io). Surgió de un convenio entre el Programa de Estudios en Ciencias Culturales y Aplicadas de Antropología de la Universidad de Cornell y el Instituto Indigenista Peruano, siendo financiado por la Carnegie Foundation de Nueva York. Mario C. Vázquez

31] «Resolución Suprema n 118 de 11 de junio de 1949», Perú Indígena, 1949, I, 2, pp. 44 y 46. 
formó parte del equipo desde su diseño inicial (GONSALES, 2OII: I48) ${ }^{32}$. Llegando a ser director de campo de la estación experimental (1957-62) y coordinador de investigación (1964). En general se considera a Vázquez alumno de Holmberg, sobre todo tomando de punto de partida su tesis de doctorado — La antropología culturaly nuestro problema del indio. Vicos: un caso de antropología aplicada (1952)-, que, en palabras de Pablo Sandoval, «resume bien el tránsito del indigenismo antropológico a las propuestas de modernización» (SANDOval, 20I4: IO5, nota II). Sin embargo, ya apuntamos que Holmberg participó en la reunión de Iquitos de la IIHA y un año después, en I949, M. Vázquez redactó un estudio preliminar de la hacienda $V i \cos ^{33}$ y en 1950 ambos publicaron una reflexión científica sobre un proyecto de antropología aplicada (HOLMBERG y vázQUEZ, 1950). Por consiguiente, debemos retrotraernos a la expedición al Huallaga de 1948, donde confluyeron modelos científicos dirigidos a la transferencia de conocimientos y orientados al diseño de políticas de intervención social, coyuntura fundacional de la antropología aplicada. Una realidad auspiciada desde la unesco y en la que convergieron la influencia de la etnología francesa y norteamericana, junto a campo indigenista peruano todavía difuso, en el que coexistían médicos con preocupaciones sociales, junto a las primeras promociones de antropólogos nacionales.

Vázquez representó al antropólogo comprometido políticamente y dispuesto a implicarse en las políticas estatales radicales de transformación. Vinculado políticamente al APRA, durante el gobierno militar de Velasco Alvarado (I968-1975) fue nombrado director de la Dirección General de Reforma Agraria, desde donde influyó decisivamente en la promulgación de la legislación relativa a las comunidades campesinas. A su vez, ayudó a la consolidación de la antropología tropical en el Perú. Según testimonio de Stefano Varese —uno de los primeros egresados en antropología «amazónica» y miembro-fundador del Centro de Investigaciones de Selva del Instituto Raúl Porras Barrenechea de la Universidad Nacional Mayor de San Marcos, creado en 1964-, fue Vázquez, lector atento de sus aportes sobre los grupos étnicos de la selva central, en especial de su obra La Sal de los Cerros

32] Los prolegómenos datan de 1947, si bien se concretarían a fines de 1951 ya durante el gobierno del general Manuel Odria.

33] Allan R. Holmberg collection on Peru, c.1946-1966, http://rmc.library.cornell.edu/EAD/htmldocs/ RMA01529.html (último ingreso: 24/06/2019). 
(1968), quien le invitó a «entrar en el equipo de la revolución velasquista», para asumir la División de Comunidades Nativas de la Selva donde

«volví a encontrar a los indígenas de la selva, no como sujetos de mis propios intereses intelectuales y etnológicos sino como agentes de su propia historia, como pobladores/ ciudadanos de insospechados universos cuya comprensión implicaba la tarea monumental de intentar traducir esos mundos a la narrativa legal, política y cultural del intolerante Perú criollo y mestizo» (VARESE, 20II: 25-27).

lo que se concretó bajo su inspiración en la Ley de Comunidades Nativas y de Promoción Agropecuaria de Regiones de Selva y Ceja de Selva de 1974 (Decreto Ley no 20653), la primera legislación que amparó los derechos sobre territorios y recursos de los grupos étnicos amazónicos.

\section{CONCLUSIONES}

La coyuntura pos IIGM trajo consigo la creación y consolidación de organismos multilaterales dedicados al favorecer al unísono cultura, saberes y desarrollo económico. Éstos dieron espacio profesional e intelectual a especialistas y técnicos internacionales, pero también ayudaron de forma indirecta a la consolidación de determinados saberes expertos nacionales, vinculados en parte al campo indigenista. Se impuso el estudio de campo o exploración-expedición científica y redacción de informes, que incluían recomendaciones de intervención social. En esa coyuntura se constituyó en el Perú la antropología como saber universitario y profesional, al influjo de dos tradiciones representadas por el indigenismo nacional y la antropología cultural aplicada norteamericana, que dio lugar a una larga tradición de estudio de comunidades y de acción política, que desembocarían en activismo durante el gobierno del general Velasco Alvarado, influyendo en la reforma agraria y la legislación indígena del periodo. La Amazonía tuvo un papel clave en la construcción del imaginario científico y de los saberes de estado.

La sensación de fracaso por haberse escogido una región equivocada fue asumida por Alfred Metraux quien escribiría que 
"du point de vue ethnographique, le choix du Huallaga était malheureux. Non seulement la population indienne originale avait presque entièrement disparu de la région, mais toute cette aire avait subi depuis la plus haute antiquité des influences culturelles venues des Andes qui avaient profondément altéré son caractère amazonien» (METRAUX, 1949: 177).

En cierta forma la cita indica el camino que seguiría cierta antropología que buscaría insistentemente al indio puro en los trópicos. Por contra, emergía desde presupuestos científicos nacionalistas peruanos, la necesidad de dirigir la investigación a la relación hombre-medio natural, para definir las políticas públicas de colonización. La etnología devenía entonces en un instrumento para redefinir la acción del estado, ante el aparente fracaso de la integración amazónica. Ello conducía a la antropología aplicada, que ocuparía un lugar preferente en un Perú, que viviría profundas transformaciones sociales a partir de la década de 1960. Podemos apuntar que, en el Perú, antes que la sociología de raíz durkhemniana, serían el indigenismo, la medicina social y la antropología aplicada los que darían las recetas para lograr la anhelada cohesión social.

\section{Referencias bibliográficas}

AUROI, CLAUDE (2004): «Fascinación y cansancio: Alfred Métraux en los Andes (1930-1962)», en: Revista andina, $\mathrm{n}^{\circ} 38$, pp. 253-279.

BUITRÓN, ANÍBAL (1942), Indios, blancos y mestizos en Otaval», en: Acta Americana, 3, pp. 190-216. BUITRÓN, ANÍBAL (1947), El campesino de la provincia de Pichincha, Quito, Instituto Nacional de Previsión.

BUITRÓN, ANÍBAL (1948): «Vida y pasión del Campesino Ecuatoriano», en: América Indígena, vol. 2, no VIII, pp. 113-130.
BUSTÍOS, CARLOS (2014): La malaria y el dengue en la historia de la salud pública peruana: 18212011. Lima, UNMSM. http://bvs.minsa.gob.pe/ local/minsa/3425.pdf (consultado el 01/07/2019). CUETO, MARCOS (1997): El regreso de las epidemias: salud y sociedad en el Perú del siglo XX, Lima, IEP.

CUETO, MARCOS (2001): «Un médico alemán en los Andes: la visión médico social de MaximeKuczynskiGodard», en: Allpanchis, n 56, pp. 39-74. 
CUVI, NICOLÁS (2011): «Dejen que el diablo haga lo demás»: la promoción de productos complementarios en América Latina durante la década de 1940», en:Historia Crítica, 44, pp. 158-181. DEGREGORI, CARLOS IVÁN (1995): «El estudio del otro: cambios en los análisis sobre etnicidad en el Perú», en Cotler, Julio (ed.), Perú 1964-1994. Economía, Sociedad y Política. Lima, IEP, pp. 303-332.

DIEZ, ALEJANDRO (2011): «Leyendo a Fuenzalida», en: Anthropologica, n 29, pp. 233-248.

GARCÍA, URIEL (2009): «Pedro Weiss, biólogo del Perú», en: Revista Peruana de medicina experimental y salud pública, vol. $3, n^{\circ} 26, p p$. 400-404.

GIL-RIAÑO, SEBASTIÁN (2014): Historicizing AntiRacism: UNESCO's Campaigns Against Race Prejudice in the 1950s, Toronto, Universidad de Toronto, tesis inédita.

GIRAUD0, LAURA (2006): «No hay propiamente todavía Instituto»: Los inicios del Instituto Indigenista Interamericano (abril 1940-marzo 1942)», en: América indígena, LXII, 2, pp. 6-32.

GIRAUDO, LAURA Y MARTÍN-SÁNCHEZ, JUAN (EDS.) (2011): La ambivalente historia del indigenismo. Campo interamericano y trayectorias nacionales, 1940-1970, Lima, IEP.

GONSALES, OSMAR (2008): «Indigenismo, Nación y Política, 1904-1930», en: Revista Intellectus, vol. I, no 7, pp. 433-454.

GONSALES, OSMAR (2011): «EI Instituto Indigenista Peruano: una historia por conocer», en Giraudo, Laura y Martín-Sánchez, Juan (eds. ), La ambivalente historia del indigenismo. Campo interamericano y trayectorias nacionales, 1940-1970, Lima, IEP, pp. 133-158

GONZÁLEZ LEANDRI, RICARDO Y SURIANO, JUAN (EDS.) (2017): La cuestión social y sus itinerarios de difusión a través de las publicaciones periódicas argentinas (1870-1930). Buenos Aires, Global South.

HOLMBERG, ALLAN R. Y VÁZQUEZ, MARIO C. (1950): «Un proyecto de antropología aplicada en el Perú», en: Revista del Museo Nacional, 19-20, pp. 311-320.

INFORME SOBRE EL HUALLAGA (ISH) (1950), Lima, Ministerio de Relaciones Exteriores.

LAURIERE, CHRISTINE, (2008): Paul Rivet (18761958), le savant et le politique. París, Editions scientifiques du Muséum national d' Histoire naturelle.

MAGALHÃES, RODRIGO; DA SILVA, CESAR; MAIO, MARCOS CHOR (2007): «Desenvolvimento, ciência e política: o caso do Instituto Internacional da Hiléia Amazônica (1946-1951)» en: História, Ciências, Saúde-Manguinhos, 14, pp. 169-189.

MAI0, MARCOS CHOR (2004): «Demandas globais, respostaslocais: a experiência da Unesco na periferia no pós-guerra (1946-1952)», en: Maio, Marcos Chor (org.), Ciência, política e relações internacionais, Rio de Janeiro, Fiocruz, UNESCO. MAI0, MARCOS CHOR (2005): «A Unesco e o projeto de criação de umlaboratório científico internacional na Amazônia», en: EstudosAvançados, 19.53, pp. 115-130.

MAIO, MARCOS CHOR; SÁ, MAGALI ROMERO (2000): "Ciência na periferia: a Unesco, a proposta de criação do Instituto Internacional da HiléiaAmazônica e as origens do Inpa», en: História, Ciências, Saúde-Manguinhos, 6, pp. 975-1017.

MAIO, MARCOS CHOR; SILVA, N. (2009): «O projeto de criação do Instituto Internacional da Hiléia Amazônica e as Ciências Sociais no contexto do Desenvolvimento», https://halshs.archivesouvertes.fr/ file/index/docid/116956/filename/PP2000_IIHA_ FGV.pdf (último ingreso: 02/01/2019).

METRAUX, ALFRED (1949): «Les enquêtes ethnographiques dans le bassin de l'Amazone en 1948», 
en: Journal de la Société des américanistes, 38, pp. 177-181.

MITCHEL, WILLIAM P. (2010): «Esperanza Antropológica y Realidad Social. El proyecto Vicos de Cornell vuelto a examinar», en: Bolton, Ralph, Greaves, Tom y Zapata, Florencia (eds.), 50 años de antropología aplicadas en el Perú: Vicos y otras experiencias, Lima, IEP, pp. 123-152. PETITJEAN, PATRICK; DOMINGUES, HELOISA MARIA BERTOL (2001): «A Unesco, O Instituto Internacional da HileiaAmazonica e a antropologia no final dos anos 40", en: Conhecimento e fronteira: história da ciência na Amazônia, pp. 83-109.

SALA i VILA, NÚRIA (2007): «Ingenieros y colonización amazónica en el Perú»,en: Anuario IEHS, 21, pp. 441-466.

SALA i VILA, NÚRIA (2016): "Saberes, ciencias y política en la formación del Estado en el Perú», en: Grompone, Romeo (ed.), Incertidumbre y distancias. El controvertido protagonismo del Estado en el Perú, Lima, IEP, pp. 147-174.

SANDOVAL, PABLO (2012): «Antropología y antropólogos en el Perú: discursos y prácticas en la representación del indio, 1940-1990», en Degregori, Carlos Iván, Sendón, Pablo F. y Sandoval, Pablo (eds.), No hay país más diverso: compendio de antropología peruana II, Lima, IEP, pp. 98-145. STEWARD, JULIAN H. Y MÉTRAUX, ALFRED (1948): «Tribes of the Peruvian and Ecuadorian Montaña», en:
Steward, Julian H. (ed.), Handbook of South American Indians, vol 3: The Tropical Forest Tribes, en: Smithsonian Institution Bureau of American Ethnology Bulletin, 143, pp. 535-656. VALCÁRCEL, LUIS E. (1981): Memorias, Lima, IEP. VARESE, STEFANO (2011): «Amazonía: ¿cuarenta años de diálogo antropológico o de monólogo ideológico?», en: Chaumeil, J.-P., Espinosa, Oscar y Cornejo, Manuel (eds.) Por donde hay soplo. Estudios amazónicos en los países andinos, Lima, IFEA-PUCP-CAAAP-Centre EREA de LESC, pp. 21-37.

VÁZQUEZ, MARIO (1949): El primitivo poblador del Huallaga y causas de su extinción. Lima, Facultad de Letras y Pedagogía, Universidad Nacional Mayor de San Marcos, tesis bachiller en etnología inédita.

WEISS, PEDRO (1924): Informe presentado por la comisión organizada por la Dirección de Salubridad para estudiar la región del Madre de Dios, Lima, Imp. Americana.

WEISS, PEDRO (1959): «Los Lamas son un pueblo misterioso y legendario que vive en el Huallaga: historia y costumbres», en: Perú Indígena, 8, 18-19, pp. 13-26.

WEISS, PEDRO; URTEAGA, OSCAR; GONZÁLEZ, L. (1942): «Contribución al estudio de la patología de la selva. Estudios médicos en Yurimaguas», en: Anales de la Facultad de Medicina, XXV, 2, pp. 149-181. 